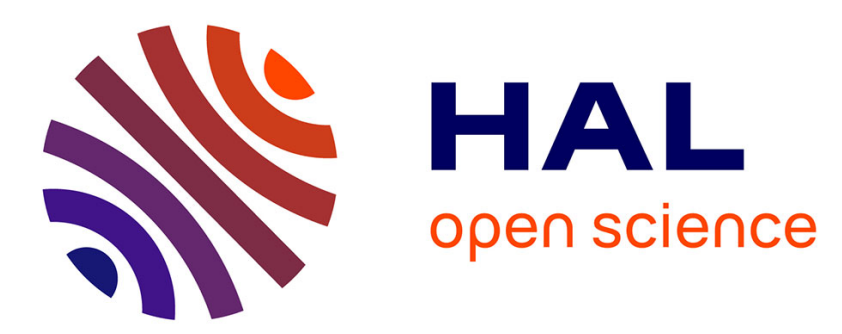

\title{
The contribution of grain boundary barriers to the electrical conductivity of titanium oxide thin films
}

Nicolas Martin, Aurélien Besnard, Fabrice Stahl, Corinne Nouveau

\section{To cite this version:}

Nicolas Martin, Aurélien Besnard, Fabrice Stahl, Corinne Nouveau. The contribution of grain boundary barriers to the electrical conductivity of titanium oxide thin films. Applied Physics Letters, 2008, 93 (6), pp.064102-3. 10.1063/1.2970034 . hal-00981143

\section{HAL Id: hal-00981143 \\ https://hal.science/hal-00981143}

Submitted on 21 Apr 2014

HAL is a multi-disciplinary open access archive for the deposit and dissemination of scientific research documents, whether they are published or not. The documents may come from teaching and research institutions in France or abroad, or from public or private research centers.
L'archive ouverte pluridisciplinaire HAL, est destinée au dépôt et à la diffusion de documents scientifiques de niveau recherche, publiés ou non, émanant des établissements d'enseignement et de recherche français ou étrangers, des laboratoires publics ou privés. 


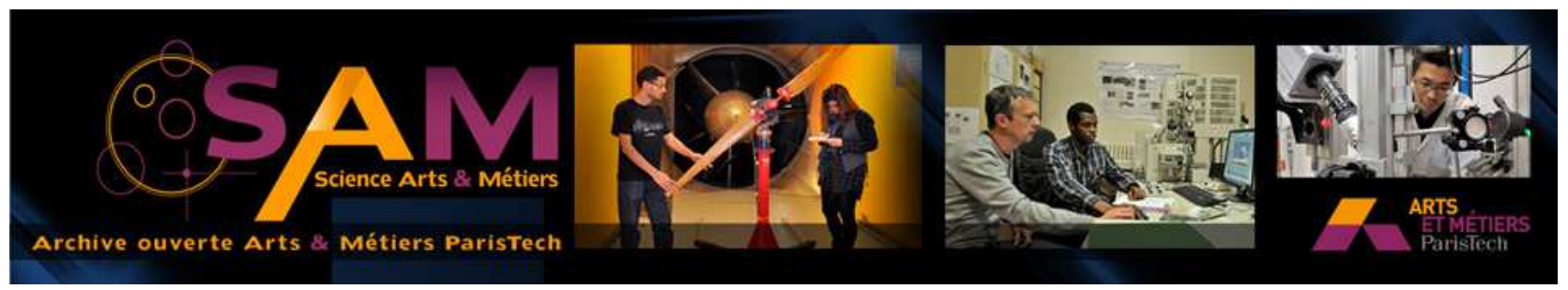

Science Arts \& Métiers (SAM)

is an open access repository that collects the work of Arts et Métiers ParisTech researchers and makes it freely available over the web where possible.

This is an author-deposited version published in: http://sam.ensam.eu

Handle ID: .http://hdl.handle.net/10985/8014

\section{To cite this version :}

Nicolas MARTIN, Aurélien BESNARD, Fabrice STAHL, Filipe VAZ, Corinne NOUVEAU - The contribution of grain boundary barriers to the electrical conductivity of titanium oxide thin films Applied Pysics Letters - Vol. 93, n6, p.064102-3 - 2008 


\title{
The contribution of grain boundary barriers to the electrical conductivity of titanium oxide thin films
}

\author{
Nicolas Martin, ${ }^{1, a)}$ Aurélien Besnard, ${ }^{1}$ Fabrice Sthal, ${ }^{1}$ Filipe Vaz, ${ }^{2}$ and Corinne Nouveau ${ }^{3}$ \\ ${ }^{1}$ Institut FEMTO-ST, 6174 CNRS, Université de Franche-Comté ENSMM UTBM 26, \\ Chemin de l'épitaphe, 25030 Besancon Cedex, France \\ ${ }^{2}$ Departamento Fisica, Universidade do Minho, Azurém, 4800-058 Guimarães, Portugal \\ ${ }^{3}$ LaBoMaP, Arts et Métiers ParisTech de Cluny, Rue Porte de Paris, 71250 Cluny, France
}

(Received 14 May 2008; accepted 23 July 2008; published online 12 August 2008)

\begin{abstract}
Titanium oxide thin films were prepared by reactive magnetron sputtering. The reactive gas pulsing process was implemented to control the oxygen injection in the deposition process and, consequently, to tune the oxygen concentration in the films from pure titanium to stoichiometric $\mathrm{TiO}_{2}$, maintaining a homogeneous in-depth concentration. The electrical conductivity of the films was investigated as a function of the oxygen injection time, the metalloid concentration and temperature, in the range 90-600 K. The curved Arrhenius plots of the conductivity were examined taking into account the grain boundary limited transport model of Werner (J. H. Werner [Solid State Phenom. 37-38, 213 (1994)]). The grain barrier heights were found to depend significantly on the oxygen supplied into the deposition process and thus, on the oxygen-to-titanium atomic ratio in the films. The analysis as a function of temperature showed that the conduction mechanism in the coatings was not solely limited by the oxygen-to-titanium atomic ratio, but also by the grain boundary scattering. (C) 2008 American Institute of Physics. [DOI: 10.1063/1.2970034]
\end{abstract}

The conductivity of polycrystalline films is sensitively related to the potential barriers and space charge regions that are built up around grain boundaries. ${ }^{1}$ A strong temperature dependence of the electrical conductivity is commonly observed in metallic and semiconducting films. Furthermore, it is shown that the grain boundaries of polycrystalline semiconductors have a significant influence on the electronic properties. According to the grain boundary model of Seto, ${ }^{2}$ if trap states in the intergranular region are present, the capture of the free carriers occurs and thus, the films' conductivity changes. These charged states create potential barriers space charge regions that are built up around the grain boundaries, which then increase the resistance between two neighboring grains. This letter demonstrates that the Werner's theory ${ }^{3}$ can be applied to the electrical conductivity behavior versus temperature of titanium oxide thin films. Experimental results showed that for the conduction mechanism, and beyond the oxygen-to-titanium atomic ratio, the transition from metallic- to semiconducting-type behavior of titanium oxide, $\mathrm{TiO}_{x}$ thin films (with $x$ varying from 0 to 2.0) has also an important contribution from the grain boundary scattering.

The $\mathrm{TiO}_{x}$ films were deposited on glass and (100) $\mathrm{Si}$ substrates by de reactive magnetron sputtering from a titanium metallic target (purity 99.6\%) in an $\mathrm{Ar}+\mathrm{O}_{2}$ gas mixture. The titanium target was sputtered with a constant current density $J=100 \mathrm{~A} \mathrm{~m}^{-2}$ while the substrates were grounded and kept at room temperature. Argon mass flow rate was set constant in order to reach an Ar partial pressure of $0.25 \mathrm{~Pa}$. Oxygen was introduced using a rectangular modulation pattern of the mass flow rate by means of a re-

\footnotetext{
a) Author to whom correspondence should be addressed. Tel.: +33 (0) 381 $\begin{array}{llllllllll}40 & 28 & 79 & \text { FAX: }+33 & (0) & 3 & 81 & 40 & 28 & 52 . \\ \text { Electronic mail: }\end{array}$ nicolas.martin@ens2m.fr.
}

active gas pulsing process. ${ }^{4-7}$ A constant pulsing period $P=45 \mathrm{~s}$ was used, whereas the time of injection $t_{\mathrm{ON}}$ of the oxygen gas was systematically changed from $0 \%$ to $100 \%$ of the period $P$. The maximum oxygen flow rate was 0.80 SCCM (SCCM denotes cubic centimeter per minute at $\mathrm{STP}$ ) during the $t_{\mathrm{ON}}$ time whereas the minimum flow was 0 SCCM during the $t_{\mathrm{OFF}}$ time (oxygen injection completely stopped). The deposition time was adjusted in order to deposit thin films with a constant thickness close to $400 \mathrm{~nm}$. The crystallographic structure was investigated by x-ray diffraction (XRD) using monochromatic $\mathrm{Cu} K_{\alpha}$ radiation at a grazing angle $\theta=1^{\circ}$. The chemical composition of the films deposited on silicon wafer (100) was determined by Rutherford backscattering spectroscopy (RBS) and nuclear reaction analysis (NRA). The electrical conductivity of the films deposited on glass substrates was measured in the Van der Pauw geometry for temperatures ranging from 90 to $600 \mathrm{~K}$.

Werner's theory assumes that the fluctuating barrier heights are described by a Gaussian probability distribution, ${ }^{3}$

$$
P(\phi)=\frac{1}{\sigma_{\phi} \sqrt{2 \pi}} e^{(\bar{\phi}-\phi)^{2} / 2 \sigma_{\phi}^{2}},
$$

where $\bar{\phi}$ denotes the mean barrier height and $\sigma_{\phi}$ denotes its standard deviation. The current across the spatially inhomogeneous grain barriers is limited by the lowest barrier in the Gaussian distribution. In addition, Werner's theory shows that the slopes of the Arrhenius plots of conductivities are curved upward with decreasing the reverse temperature values. The curved behavior of the plots $\ln (\sigma / T)$ is well fitted by a parabola, following:

$$
\ln \left(\frac{\sigma}{T}\right)=\frac{a}{T^{2}}-\frac{b}{T}-c .
$$

The mean barrier height $\bar{\phi}$ and the standard deviation $\sigma_{\phi}$ are 


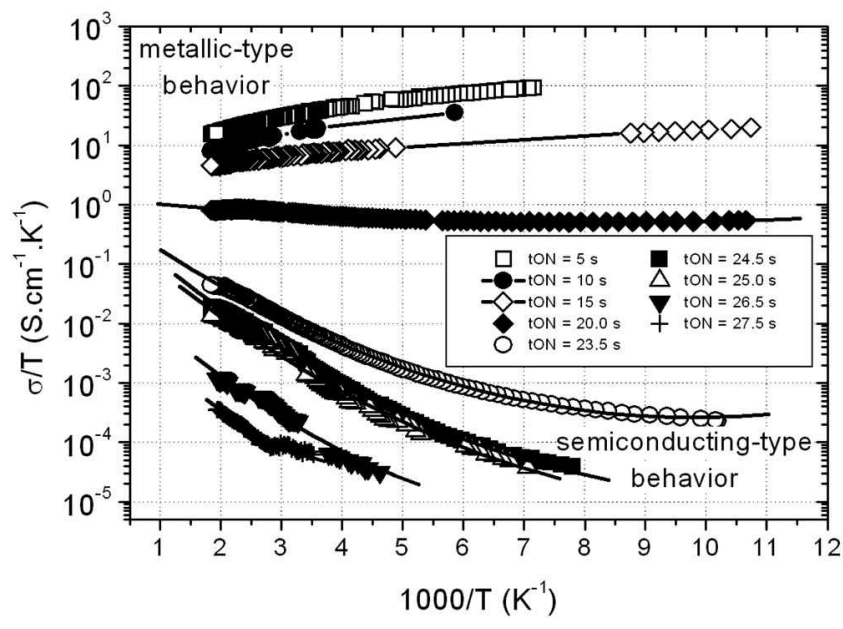

FIG. 1. Temperature dependence of the electrical conductivity of $\mathrm{TiO}_{x}$ films sputter deposited by the reactive gas pulsing process using various times of injection of the oxygen gas.

$$
\begin{aligned}
& \sigma_{\phi}=\sqrt{\frac{2 a k^{2}}{q^{2}}}, \\
& \bar{\phi}=\frac{b k}{q},
\end{aligned}
$$

where $k=1.38 \times 10^{-23} \mathrm{~J} \mathrm{~K}^{-1}$ and $q=1.6 \times 10^{-19}$ A s.

Figure 1 illustrates the temperature dependent conductivity $\ln (\sigma / T)$ for sputtered $\mathrm{TiO}_{x}$ thin films in the temperature range 90 to $600 \mathrm{~K}$. The obtained results can be separated in two groups. The first one concerns $\mathrm{TiO}_{x}$ thin films sputter deposited with $t_{\mathrm{ON}}$ injection times up to $15 \mathrm{~s}$. Electrical conductivity at room temperature ranges from $\sigma_{293 \mathrm{~K}}=1.10$ $\times 10^{4}$ to $2.14 \times 10^{3} \mathrm{~S} \mathrm{~m}^{-1}$, which corresponds to conventional metallic $\mathrm{TiO}_{x}$ thin film values. ${ }^{8}$ For coatings deposited with $t_{\mathrm{ON}}=5$ and $10 \mathrm{~s}$, a typical metallic behavior is observed as a function of temperature. The temperature coefficient of resistance $\left(\mathrm{TCR}_{293 \mathrm{~K}}\right)$ calculated at $293 \mathrm{~K}$ is reduced from $1.33 \times 10^{-3}$ to $6.80 \times 10^{-4} \mathrm{~K}^{-1}$ (Table I). It becomes negative for $t_{\mathrm{ON}}=15 \mathrm{~s}\left(\mathrm{TCR}_{293 \mathrm{~K}}=-1.01 \times 10^{-3} \mathrm{~K}^{-1}\right)$. Such a decrease of TCR with $\mathrm{O} / \mathrm{Ti}$ ratio is in agreement with Banakh et al. ${ }^{8}$ investigations focused on $\mathrm{TiO}$ metallic films. Negative TCR values tend to appear in $\mathrm{TiO}_{x}$ thin films where the low free carrier concentration results in a less efficient screening of the point defects. Understanding electrical transport in such $\mathrm{TiO}_{x}$ metallic systems (point defect concentration reaches several at. \%) is still an open question. However, the decrease of TCR versus $\mathrm{O} / \mathrm{Ti}$ ratio and its negative value reached for $t_{\mathrm{ON}}=15 \mathrm{~s}$ can be related to the Mooij criterion (at room temperature, resistivity of $150 \mu \Omega \mathrm{cm}$ is an universal criterion for the sign of TCR; if the room temperature resistivity of a sample is larger than this value, it is likely to have a negative TCR). ${ }^{9}$ Such a criterion applied in a large number of amorphous or disordered metal conductors remains one of the most criteria applied to explain the negative TCR values in metallic compounds. ${ }^{10}$ Similarly, Riess et al. ${ }^{1}$ explained the change of sign of the calculated TCR from positive to negative values taking into account the number of grain boundaries per electron mean free path. For our results, an increase of the $t_{\mathrm{ON}}$ injection time obviously leads to an oxygen enrichment of $\mathrm{TiO}_{x}$ films, but specially the long range order is reduced (from XRD, metallic crystallite size calculated from Scherrer's method reduces from 30 to $5 \mathrm{~nm}$ as $t_{\mathrm{ON}}$ changes from 5 to $15 \mathrm{~s}$ ). Thus, assuming the same electron mean free path for all $\mathrm{TiO}_{\mathrm{x}}$ films exhibiting metallic behaviors $\left(t_{\mathrm{ON}}=5-15 \mathrm{~s}\right)$, the number of grain boundaries is enhanced and a negative TCR value can be expected, although the electrical conductivity decreases versus temperature.

The second group of samples involves $\mathrm{TiO}_{\mathrm{x}}$ thin films prepared with $t_{\mathrm{ON}}$ injection times higher than $20 \mathrm{~s}$. Conductivity at room temperature is continuously decreasing from $\sigma_{293 \mathrm{~K}}=2.53 \times 10^{2}$ to $2.86 \times 10^{-2} \mathrm{~S} \mathrm{~m}^{-1}$ as $t_{\mathrm{ON}}$ increases from 20 to $27.5 \mathrm{~s}$. For this kind of films, a characteristic semiconducting behavior is measured as a function of temperature. For semiconductors, the Arrhenius plot of the conductivity versus the reverse of the temperature usually exhibits a linear evolution for temperatures higher than the room temperature. The activation energy $E_{a}$, which gives evidence that the conduction mechanism is thermally activated can be then calculated. Table I shows that the calculated value for the energy $E_{a}$ increase from 30 to $190 \mathrm{meV}$ as the $t_{\mathrm{ON}}$ time increases. It tends to that of stoichiometric $\mathrm{TiO}_{2}$ compound $\left[E_{a}=650 \mathrm{meV}\right.$ (Ref. 11)], which correlates with O/Ti ratios determined by RBS and NRA. As the temperature range extends (from 90 to $600 \mathrm{~K}$ ), Arrhenius plots become curved (Fig. 1) and Werner's theory is relevant to determine the mean heights of the barrier potential $\bar{\phi}$ and the standard deviation $\sigma_{\phi}$ following Eqs. (3) and (4). Measured conductivities of $\mathrm{TiO}_{x}$ thin films deposited at high $t_{\mathrm{ON}}$ times are well described by parabola in agreement with Eq. (2). Parameters $\bar{\phi}$ and $\sigma_{\phi}$ have been calculated from conductivity measurements versus temperature in Fig. 1 and for rising $t_{\mathrm{ON}}$ injection times (Fig. 2). Both parameters increase with $t_{\mathrm{ON}}$ injection time. The mean barrier height changes from 8 to $113 \mathrm{meV}$ and the standard deviation from 9 to $40 \mathrm{meV}$ as the $t_{\mathrm{ON}}$ time increases from 20 to $27.5 \mathrm{~s}$. Werner ${ }^{3}$ also proposed a homogeneity coefficient $H$ defined as the ratio of

TABLE I. Chemical composition, electrical behaviors, and structure of $\mathrm{TiO}_{x}$ thin films as a function of the $t_{\mathrm{ON}}$ time. am. denotes amorphous and $\mathrm{N}$. A. denotes

\begin{tabular}{|c|c|c|c|c|c|c|c|c|c|}
\hline$t_{\mathrm{ON}}(\mathrm{s})$ & 5.0 & 10.0 & 15.0 & 20.0 & 23.5 & 24.5 & 25.0 & 26.5 & 27.5 \\
\hline [O] (at. \%) & 9.8 & 33.7 & 51.3 & 58.9 & 64.1 & 64.8 & 65.6 & 66.6 & 66.6 \\
\hline $\mathrm{O} / \mathrm{Ti}$ ratio & 0.11 & 0.51 & 1.05 & 1.43 & 1.79 & 1.84 & 1.91 & 1.99 & 1.99 \\
\hline$\sigma_{293 \mathrm{~K}}\left(\mathrm{~S} \mathrm{~m}^{-1}\right)$ & $1.10 \times 10^{4}$ & $5.13 \times 10^{3}$ & $2.14 \times 10^{3}$ & $2.53 \times 10^{2}$ & 4.30 & 1.62 & 1.27 & $1.12 \times 10-^{1}$ & $2.86 \times 10-^{2}$ \\
\hline Behaviors & \multicolumn{3}{|c|}{$\leftarrow$ metallic $\rightarrow$} & \multicolumn{6}{|c|}{$\leftarrow$ semiconducting $\rightarrow$} \\
\hline $\mathrm{TCR}_{293 \mathrm{~K}}\left(\mathrm{~K}^{-1} \times 10^{3}\right)$ & 1.33 & 0.68 & -1.01 & \multicolumn{6}{|c|}{ N.A. } \\
\hline$E_{a}(\mathrm{meV})$ & \multicolumn{3}{|c|}{ N.A. } & 30 & 140 & 160 & 150 & 190 & 160 \\
\hline Structure by XRD & $\leftarrow \mathrm{Ti} \rightarrow$ & \multicolumn{2}{|c|}{$\leftarrow$ am. + fcc $\mathrm{TiO} \rightarrow$} & \multicolumn{6}{|c|}{$\leftarrow$ am. $+\mathrm{TiO}_{2}$ anatase and rutile $\rightarrow$} \\
\hline
\end{tabular}
not applicable. 


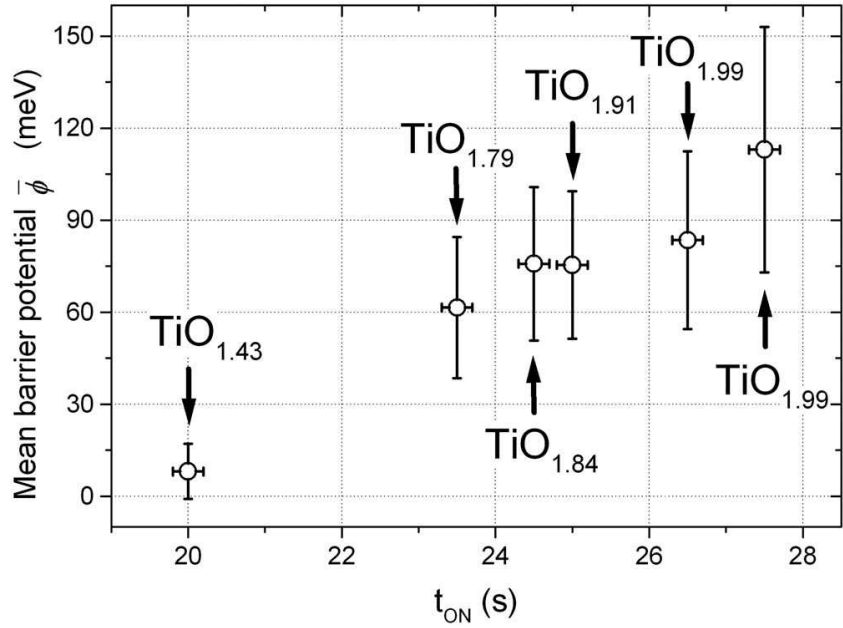

FIG. 2. Mean height of the barrier potential $\bar{\phi}$ vs $t_{\mathrm{ON}}$ injection time of the oxygen gas. Composition of the $\mathrm{TiO}_{\mathrm{x}}$ films is also indicated. Error bars of the energy axis represent the standard deviation $\sigma_{\phi}$.

$\bar{\phi}$ to $\sigma_{\phi}$. The larger the $\mathrm{H}$, the more homogeneous is the film. For our $\mathrm{TiO}_{x}$ thin films, the $H$ coefficient is enhanced from 0.88 to 3.1 with the $t_{\mathrm{ON}}$ injection time, which are typical values previously reported for other semiconducting compounds. $^{12-14}$

In undoped and substoichiometric $\mathrm{TiO}_{2}$ thin films, it is commonly admitted that the conductivity change is closely linked to the mobile charge carriers. ${ }^{15}$ Their concentration originates from point defects, i.e., mainly oxygen vacancies rather than interstitial titanium atoms. The contribution of the oxygen vacancies to the conductivity mechanism predominates for titanium oxide thin films exhibiting semiconducting behaviors and prepared with low $t_{\mathrm{ON}}$ times (e.g., $\mathrm{O} / \mathrm{Ti}$ ratio $=1.43-1.91)$. In addition, the mean heights of the barrier potential are the lowest for the corresponding range of the $t_{\mathrm{ON}}$ time $\left(\bar{\phi}=8 \mathrm{meV}\right.$ for $\left.t_{\mathrm{ON}}=20 \mathrm{~s}\right)$, which correlates with a conductivity behavior determined by the oxygen vacancies. For the highest $t_{\mathrm{ON}}$ times, $\mathrm{O} / \mathrm{Ti}$ ratio tends to the stoichiometric $\mathrm{TiO}_{2}$ compounds. The oxygen vacancies concentration is reduced whereas the mean height of the barrier potential is higher than $110 \mathrm{meV}$. As a result, conductivity is mainly influenced by grain boundary effects and prevails on the point defects.
Summarizing, we have produced $\mathrm{TiO}_{x}$ thin films by reactive sputtering using a pulsed injection of the oxygen gas (reactive gas pulsing process). A systematic change of the $t_{\mathrm{ON}}$ injection time of the reactive gas leads to tunable electrical properties of titanium oxides, in agreement with investigations involving other deposition techniques. ${ }^{16-18}$ For $\mathrm{O} / \mathrm{Ti}$ atomic ratios close to or lower than one, a metallic behavior is clearly observed with positive and negative TCR values closely linked to the number of grain boundaries per electron mean free path. Titanium oxide semiconducting films are prepared for longer $t_{\mathrm{ON}}$ injection times. Conductivity behaviors are found to be not solely ruled by the oxygen vacancies, but also by the potential at the grain boundaries. Point defects prevail for oxygen-deficient titanium dioxide, whereas the heights of the barrier potential become predominant for thin films tending to the stoichiometric $\mathrm{TiO}_{2}$ compound.

${ }^{1}$ G. Reiss, J. Vancea, and H. Hoffman, Phys. Rev. Lett. 56, 2100 (1986).

${ }^{2}$ J. Y. W. Seto, J. Appl. Phys. 46, 5247 (1975).

${ }^{3}$ J. H. Werner, Solid State Phenom. 37, 213 (1994).

${ }^{4}$ N. Martin, A. R. Bally, P. Hones, R. Sanjinès, and F. Lévy, Thin Solid Films 377, 550 (2000).

${ }^{5}$ N. Martin, J. Lintymer, J. Gavoille, J. M. Chappé, F. Sthal, J. Takadoum, F. Vaz, and L. Rebouta, Surf. Coat. Technol. 201, 7720 (2007).

${ }^{6}$ N. Martin, J. Lintymer, J. Gavoille, J. M. Chappé, F. Sthal, J. Takadoum, F. Vaz, and L. Rebouta, Surf. Coat. Technol. 201, 7727 (2007).

${ }^{7}$ N. Martin, J. Lintymer, J. Gavoille, J. M. Chappé, F. Sthal, J. Takadoum, F. Vaz, and L. Rebouta, Surf. Coat. Technol. 201, 7733 (2007).

${ }^{8}$ O. Banakh, P. E. Schmid, R. Sanjinès, and F. Lévy, Surf. Coat. Technol. 151, 272 (2002).

${ }^{9}$ J. H. Mooij, Phys. Status Solidi A 17, 521 (1973).

${ }^{10}$ D. S. MacLachlan, Phys. Rev. B 25, 2285 (1982).

${ }^{11}$ A. R. Bally, E. N. Korobeinikova, P. E. Schmid, F. Lévy, and F. Bussy, J. Phys. D: Appl. Phys. 31, 1149 (1998).

${ }^{12}$ S. Seeger, R. Mientus, J. Röhrich, E. Strub, W. Bohne, and K. Ellmer, Surf. Coat. Technol. 200, 218 (2005).

${ }^{13}$ B. Ouertani, J. Ouerfelli, M. Saadoun, B. Bessaïs, H. Ezzaouia, J. C. Bernède, Mater. Charact. 54, 431 (2005).

${ }^{14}$ J. R. Ares, A. Pascual, I. J. Ferrer, and C. R. Sanchez, Thin Solid Films 451, 233 (2004).

${ }^{15}$ H. Tang, K. Prasad, R. Sanjinès, P. E. Schmid, and F. Lévy, J. Appl. Phys. 74, 2042 (1994).

${ }^{16}$ D. Mercs, F. Lapostolle, F. Perry, A. Billard, and C. Frantz, Surf. Coat. Technol. 116, 916 (1999).

${ }^{17}$ E. K. Kim, M. H. Son, S. K. Min, Y. K. Han, C. H. Wang, and S. S. Yom, J. Appl. Phys. 79, 4459 (1996).

${ }^{18}$ H. Tang, F. Lévy, H. Berger, and P. E. Schmid, Phys. Rev. B 52, 7771 (1995) 